\title{
Los Antagonistas de los Receptores Opioides en el Tratamiento del Alcoholismo
}

\section{Opioid Receptor Antagonists in the Treatment of Alcoholism}

\author{
Josep Guardia Serecigni \\ Consultor Senior en Psiquiatría. Unidad de Conductas Adictivas. Servicio de Psiquiatría. \\ Hospital de la Santa Creu i Sant Pau de Barcelona
}

\section{Resumen}

Objetivos: A partir de los recientes progresos en la farmacoterapia del alcoholismo, hemos efectuado una revisión sobre los fármacos antagonistas de los receptores opioides, que tienen aprobada la indicación para el tratamiento del alcoholismo, como son naltrexona y nalmefeno. Metodología: Hemos revisado más de 100 publicaciones sobre péptidos y receptores opioides, el efecto de los fármacos antagonistas de los receptores opioides sobre el consumo de alcohol, tanto en animales como en humanos, tanto en el laboratorio como para el tratamiento del alcoholismo. También se describen las características farmacológicas de naltrexona y de nalmefeno y su utilidad en la práctica clínica. Resultados: Múltiples evidencias han demostrado la eficacia de naltrexona y nalmefeno para reducir el consumo de alcohol, tanto en animales de laboratorio como también en personas estudiadas en situación de bar experimental, aunque debido al diferente perfil receptorial, nalmefeno ha sido relacionado con una mayor eficacia para la reducción del consumo de alcohol, en ratas que presentan dependencia del alcohol. Además, un gran número de ensayos clínicos controlados han demostrado la eficacia de naltrexona para la prevención de recaídas, en personas que presentan un trastorno por dependencia del alcohol. Ensayos clínicos controlados recientes han demostrado la eficacia de nalmefeno "a demanda" para reducir el consumo de alcohol, en personas que presentan un trastorno por dependencia del alcohol de baja gravedad. Conclusiones: Tanto naltrexona como nalmefeno han demostrado ser fármacos seguros, bien tolerados, de manejo sencillo, y eficaces para el tratamiento del trastorno por dependencia del alcohol, (actualmente llamado trastorno por consumo de alcohol). A partir de recientes ensayos clínicos controlados se ha comprobado que nalmefeno produce una reducción significativa del consumo de alcohol, lo cual supone un nuevo objetivo que amplía las posibilidades de tratamiento para los pacientes que no desean la abstención continuada, sino una reducción de su consumo de alcohol. Palabras clave: Nalmefeno, naltrexona, antagonistas de los receptores opioides, tratamiento del alcoholismo, reducción del consumo de alcohol.

\begin{abstract}
Objectives: On the basis of the recent advances in drug therapy of alcoholism, we conducted a review on opioid receptor antagonist drugs with approved indication for the treatment of alcoholism, such as naltrexone and nalmefene. Methods: We reviewed over 100 publications on peptides and opioid receptors, as well as studies conducted in experimental animals and in humans on the effect of opioid receptor antagonists on alcohol consumption in the treatment of alcoholism. We also reviewed the pharmacological characteristics of naltrexone and nalmefene, and the usefulness of these drugs in clinical practice. Results: Much evidence has demonstrated the efficacy of naltrexone and nalmefene for the reduction of alcohol consumption, in experimental animals as well as in humans examined under experimental bar conditions; however, due to its different receptor profile, nalmefene has been associated with higher efficacy levels in reducing alcohol consumption in alcohol-dependent rats. In addition, a great number of controlled clinical trials have demonstrated the efficacy of naltrexone for relapse prevention in patients with an alcohol dependence disorder. Recent controlled clinical trials have demonstrated the efficacy of nalmefene "as-needed" in the reduction of alcohol consumption in subjects with mild alcohol dependence. Conclusions: Both naltrexone and nalmefene have proved to be safe, well tolerated, easy to manage, and efficient drugs for the treatment of alcohol dependence disorder (currently known as alcohol use disorder). On the basis of recent controlled clinical trials, nalmefene has been shown to result in a significant reduction of alcohol consumption, thereby representing a new objective that extends the therapeutic possibilities for those patients who do not wish for a continuous abstinence, but rather a reduction of alcohol consumption.

Key words: Nalmefene, naltrexone, opioid receptor antagonist drugs, alcoholism treatment, reduction of alcohol consumption.
\end{abstract}


$\mathrm{E}$ 1 ALCOHOLISMO, actualmente llamando Trastorno por Consumo de Alcohol, es el trastorno mental más prevalente entre los hombres y uno de los que tiene un bagaje de investigación científica más extenso, tanto en el laboratorio con animales, como con respecto a su diagnóstico y su tratamiento, en la práctica clínica (Guardia Serecigni, Jiménez-Arriero, Pascual Pastor, Flórez Menéndez y Contel Guillamón, 2008).

El alcoholismo es una enfermedad adictiva, probablemente asociada a un mal funcionamiento de determinados circuitos cerebrales que intervienen en el auto-control de la conducta de ingerir bebidas alcohólicas. Se caracteriza por los aspectos incentivo-motivacionales del consumo de alcohol y sus estímulos condicionados, pero también por un deterioro en la capacidad de inhibición de respuestas inapropiadas de búsqueda y consumo de alcohol (Kalivas y Volkow, 2005). Si no se detiene el curso de esta enfermedad, sus consecuencias médicas, psiquiátricas, adictivas, familiares, laborales y sociales, pueden ir empeorando progresivamente, contribuyendo a incrementar la vulnerabilidad hacia las recaídas y también a cronificar y perpetuar la enfermedad (Guardia, Surkov y Cardús, 2011).

El síntoma cardinal del alcoholismo es la dificultad para controlar el consumo de alcohol y guarda relación con el funcionamiento alterado de diversos sistemas de neurotransmisión, entre los cuales destacan los sistemas glutamatérgico, gabérgico, dopaminérgico y opioide. Los estudios de investigación preclínicos han aportado muchas evidencias científicas, que posteriormente han sido confirmadas en la práctica clínica y han sido de gran utilidad para el desarrollo del tratamiento farmacológico del alcoholismo (Guardia Serecigni, 2015).

La mayoría de fármacos que han sido estudiados para el tratamiento del alcoholismo no han llegado a ser utilizados en la práctica clínica, ya que los ensayos clínicos efectuados no han demostrado que tuvieran una eficacia superior al placebo. Los fármacos agonistas y antagonistas dopaminérgicos, los antagonistas glutamatérgicos y los agonistas GA$\mathrm{BA}_{\mathrm{A}}$ no han demostrado una clara eficacia para el tratamiento del alcoholismo (Guardia Serecigni et al., 2008; Pascual, Guardia, Pereiro y Bobes, 2013). La mayoría -aunque no todos- los ensayos clínicos controlados, efectuados en Europa, demostraron la eficacia de acamprosato para la prevención de recaídas, pero entre los últimos efectuados en Estados Unidos no se ha podido confirmar que dicho fármaco sea superior al placebo (Anton, O’Malley, Ciraulo, Cisler, Couper et al., 2006). Además, su dosificación en forma de 6 comprimidos al día, dificulta enormemente su cumplimiento para los pacientes alcohólicos y si no hay un buen cumplimiento es difícil que un fármaco pueda resultar eficaz. Respecto a topiramato, únicamente 2 ensayos clínicos controlados, que han sido dirigidos por el mismo investigador, han aportado resultados superiores a placebo (Johnson, AitDaoud, Bowden, Di Clemente, Roache et al., 2003; Johnson,
Rosenthal, Capece, Wiegand, Mao et. al., 2007), y además, ninguna autoridad sanitaria ha aprobado su indicación para el tratamiento del alcoholismo.

Entre los fármacos que han demostrado ser eficaces, y que han sido autorizados para el tratamiento del alcoholismo, destacan los fármacos antagonistas de los receptores opioides naltrexona y nalmefeno. Disponen de un bagaje científico muy completo, ya que han sido investigados tanto en animales bebedores de alcohol en exceso (ratones, ratas y monos), como con personas en situaciones de laboratorio tipo bar experimental, como mediante ensayos clínicos de tratamiento del alcoholismo (Guardia Serecigni, 2015).

La acción de los antagonistas opioides sobre el consumo de alcohol ha jugado un papel decisivo, tanto en la comprensión neurobiológica de la adicción al alcohol, como en el tratamiento farmacológico de dicha enfermedad. Algunos estudios de laboratorio, efectuados en bares experimentales, nos han ayudado a comprender como actúan naltrexona y nalmefeno para reducir el consumo de alcohol, en una sesión de beber (alcohol). Y muchos ensayos clínicos controlados, sobre el tratamiento del alcoholismo, han evaluado su eficacia y su tolerabilidad. Los estudios iniciales de los años 90 se efectuaron con la toma diaria de medicación y con el objetivo de abstención continuada de alcohol, mientras que en los más recientes se ha modificado el objetivo, que ha sido la reducción del consumo de alcohol y también la pauta posológica que ha pasado a ser "a demanda", limitada a los días u ocasiones en los que la persona se dispone a tomar bebidas alcohólicas (Guardia Serecigni, 2015).

Muchas personas que han tenido problemas, como consecuencia del consumo excesivo de alcohol, deciden dejar de beber, incluso sin la ayuda de tratamiento, cuando dichas consecuencias negativas han llegado a agobiarles. Estas personas pueden estar varias semanas sin beber y pueden mantenerse en remisión incluso durante meses o años, cuando han seguido un tratamiento especializado. Sin embargo, el día que deciden tomar una nueva consumición alcohólica, es probable que presenten importantes dificultades para controlar su consumo de alcohol y que vuelvan a presentar un consumo excesivo, junto con la rápida reaparición de las consecuencias negativas asociadas a dicho consumo excesivo (de alcohol). Esta típica secuencia de recaída suele aparecer una o varias veces a lo largo del proceso de recuperación de los pacientes alcohólicos. Sin embargo, resulta siempre inesperada y decepcionante para los familiares y puede llegar a ser devastadora para el enfermo alcohólico (Guardia Serecigni, 2011).

Diversos tratamientos del alcoholismo ayudan al paciente a "dejar" de beber y a "mantenerse" sin beber durante una temporada, pero es probable que tarde o temprano el paciente pruebe de tomar alguna consumición de contenido alcohólico y a partir de este momento puede reaparecer rápidamente su descontrol con la bebida. Es el llamado efecto de deprivación, comprobado tanto en animales como en 
personas que presentan dependencia del alcohol. Un efecto que puede ser bloqueado por los fármacos antagonistas de los receptores opioides (Sinclair, 1990; Sinclair, 2001).

Anteriormente, el único objetivo de tratamiento aceptado era el abandono completo y continuado de bebidas alcohólicas. Sin embargo, cuando el paciente alcohólico inicia el tratamiento no suele tener un claro objetivo de abstención continuada. Mas bien se propone no beber habitualmente, pero dejándose la puerta abierta a algún consumo puntual, en algún día o momento señalado, que él tiene claramente asociado con el alcohol. A partir de aquí se suele generar un mal entendido entre el médico y el paciente. El médico cree que el paciente se propone dejar de tomar bebidas alcohólicas por completo, ya que esto es lo que el paciente verbaliza. Pero el paciente, que todavía no comprende la naturaleza de su enfermedad adictiva, cree que tomar una pequeña cantidad de alcohol algún día especial, no tiene por qué interferir en su recuperación. El problema es que cuando el paciente intenta hacer un pequeño consumo de alcohol suele reaparecer la pérdida de control que le puede llevar al consumo excesivo y a sus consecuencias negativas asociadas (Guardia Serecigni, 2011).

Es decir, el verdadero objetivo de tratamiento que se proponen los pacientes alcohólicos, en la fase inicial de su recuperación, no coincide con la expectativa de abstención completa i continuada que suele tener su médico, sino más bien con el nuevo objetivo de REDUCCIÓN del consumo de alcohol, que sí permite la opción de hacer algún consumo ocasional y de bajo riesgo.

\section{Neurobiología del alcoholismo}

La administración aguda de alcohol produce una facilitación de la actividad inhibitoria del GABA, que sumada a una reducción de la actividad excitatoria del glutamato, los canales de calcio y la noradrenalina, generan un estado de enlentecimiento del Sistema Nervioso Central (SNC), que en un grado extremo de intoxicación (alcohólica) puede llegar a producir el coma y la muerte por parada cardio-respiratoria.

Sin embargo, la administración crónica de alcohol produce cambios neuroadaptativos compensatorios, que generan un estado de hiperexcitabilidad del SNC, que puede manifestarse clínicamente con los síntomas de abstinencia y que es debido, tanto a una hiperfunción glutamatérgica, noradrenérgica y de los canales de calcio, como a una hipofunción gabérgica.

En el Área Tegmental Ventral (ATV) del mesencéfalo, las neuronas dopaminérgicas se encuentran sometidas al control tónico inhibitorio de las neuronas GABA y éstas, a su vez, pueden ser activadas por las neuronas glutamatérgicas o frenadas por la neurotransmisión opioidérgica. La función de estos sistemas de neurotransmisión, que confluyen en la encrucijada del ATV, puede jugar un papel decisivo en las recaídas.
Cuando el paciente alcohólico deja de beber, suele presentar un bajo funcionamiento de su neurotransmisión dopaminérgica (un estado transitorio de hipodopaminergia), pero un nuevo consumo de alcohol va a producir una gran liberación de dopamina en regiones mesolímbicas, (debido al efecto agudo del alcohol sobre la neurotransmisión glutamatérgica, opioidérgica y gabérgica), que puede disparar estados de "craving", búsqueda y consumo de alcohol (Clapp, Bhave y Hoffman, 2008).

\section{Sistema opioide y consumo de alcohol}

El sistema opioide endógeno está implicado en diversos procesos fisiológicos como la analgesia, el estrés, la recompensa o las funciones adaptativas homeostásicas (control de la temperatura, ingesta de agua y comida). La administración aguda de alcohol produce liberación de péptidos opioides, los cuales inducen efectos reforzadores positivos y favorecen la adquisición de la conducta de auto-administración de alcohol.

Tanto la abstinencia de opiáceos como la administración de opiáceos influyen sobre el consumo de alcohol. Dosis elevadas y moderadas de morfina disminuyen la preferencia por alcohol, en proporción inversa a la dosis recibida, el mismo día de la inyección de morfina, sin embargo, al día siguiente aumenta el consumo de alcohol (Volpicelli, Ulm y Hopson, 1991). Una pequeña dosis de un agonista opioide (como la morfina) puede actuar como apetitivo o cebador ("primer") e inducir un aumento del consumo de alcohol (Reid y Hunter, 1984). Las personas que han desarrollado una dependencia de heroína, presentan un aumento del consumo de alcohol cuando sufren abstinencia (de heroína); mientras que el mantenimiento con metadona, a dosis elevadas, puede ayudarles a reducir el consumo de alcohol (Siegel, 1986).

La ingesta de alcohol también produce activación del sistema opioide, relacionada tanto con el efecto reforzador positivo del consumo de alcohol, como con la pérdida de control (Reid, 1990). Se produce, por tanto, una relación inversa entre la administración de agonistas opioides y el consumo de alcohol, de manera que tanto dosis pequeñas de opiáceos, como la abstinencia de opiáceos producen un aumento del consumo de alcohol, mientras que dosis elevadas de opiáceos disminuyen el consumo de alcohol. Lo cual sugiere que alcohol y opiáceos tienen efectos farmacológicos parecidos y que manipulando el sistema opioide endógeno se puede modificar el consumo de alcohol.

Las propiedades reforzadoras del alcohol están moduladas (por lo menos, en parte), por los receptores opioides cerebrales. Las hipótesis iniciales se orientaron hacia los productos de condensación entre acetaldehído y dopamina, que podían inducir un aumento del consumo de etanol, por estimulación directa de los receptores opioides cerebrales, como las tetra-hidro-isoquinolinas (Davis y Walsh, 1970), el salsolinol (Collins y Bigdeli, 1975) y la tetrahidropapaverolina (Greenwald, Fertel, Wong, Schwartz y Bianchine, 1979). Pero dichas hipótesis 
han sido cuestionadas, ya que los alcaloides, inducidos por el consumo de alcohol, se detectaron en tan pequeñas cantidades que no parece probable que sean fisiológicamente activos.

El sistema opioide tiene una gran complejidad, debido a las posibles conexiones entre los diversos péptidos agonistas, receptores opioides específicos y su localización en áreas cerebrales diferentes. Las neuronas endorfinérgicas, procedentes del núcleo arqueado del hipotálamo, se proyectan hacia otros núcleos hipotalámicos, del septum y del núcleo accumbens (importantes centros mediadores de los efectos de refuerzo positivo y recompensa de muchas drogas de abuso), así como también hacia la sustancia gris periacueductal, amígdala e hipocampo) (Wise y Bozarth, 1982). Las neuronas proencefalinérgicas están ampliamente distribuidas en el cerebro, con una mayor acumulación en el estriado, sustancia gris periacueductal, hipotálamo, sustancia gris periventricular, hipocampo y núcleos del rafe. Y las prodinorfinérgicas están localizadas en el hipotálamo, núcleo periventricular, córtex cerebral, amígdala, hipocampo, sustancia gris periacueductal, núcleo del tracto solitario, médula espinal, médula suprarrenal e intestino.

Las encefalinas (Met-y Leu-encefalina) van a enlazar con el receptor delta opioide, con una afinidad 25 veces mayor que con el receptor mu opioide. La beta-endorfina reconoce los lugares de enlace mu y delta, aunque se ha descrito preferencia por el receptor mu. Y las dinorfinas enlazan selectivamente con el receptor opioide kappa (Gianoulakis, 1993).

En el ATV, los opioides actuarían sobre los receptores mu, modulando las conductas recompensadas. Su activación produciría hiperpolarización de la interneurona GABA, desinhibición de la neurona dopaminérgica y aumento de liberación de dopamina en el núcleo accumbens (Johnson y North, 1992), lo cual podría favorecer la auto-administración, y podría estar relacionada con el craving de alcohol y la pérdida de control.

En el cerebro límbico anterior, los opioides activarían los receptores delta, produciendo también un aumento de liberación de dopamina en el núcleo accumbens que podría estar relacionado con el mantenimiento de la conducta de auto-administración, el craving y la recaída, en las personas con dependencia del alcohol (Van Ree, 1987).

En cepas de ratas seleccionadas por su elevado consumo de etanol, se ha propuesto que dicha predisposición puede estar relacionada con el sistema opioide, ya que los antagonistas delta opioides pueden reducir su consumo de alcohol (Altshuler, Phillips y Feinhandler, 1980; Froehlich, Harts, Lumeng y Li, 1990; Reid, 1990).

Se han detectado bajos niveles basales de beta-endorfina en personas con riesgo de alcoholismo (por tener antecedentes familiares de alcoholismo en sus tres generaciones precedentes), comparados con personas que no tenían antecedentes familiares de alcoholismo. Además, tras el consumo de 0'5 gr/ $\mathrm{kg}$ de etanol, se produjo un incremen- to transitorio de beta-endorfina plasmática en el grupo de alto riesgo, comparado con el grupo de bajo riesgo de alcoholismo (Gianoulakis, Kirshnan y Thavundayil, 1996). Por otro lado, los pacientes alcohólicos también presentarían bajos niveles de beta-endorfina, después de dejar de beber, que retornarían a la normalidad tras 6 meses de abstención continuada (de alcohol) (Gennazani, Nappi, Eacchinetti, Mezzella y Parrini, 1982).

El alcohol, en administración aguda, produce liberación de opioides endógenos, sobretodo beta-endorfina, que induce un aumento de la liberación de dopamina en el núcleo accumbens, (mediado por la acción inhibitoria de la beta-endorfina sobre las neuronas GABA del ATV). Dicho incremento en la disponibilidad de dopamina puede tener relación con su efecto reforzador positivo, el "craving" y la pérdida de control, que pueden llevar a la recaída. Por tanto, determinados fármacos que actúen sobre estos sistemas de neurotransmisión podrán modular las mencionadas alteraciones y reducir el riesgo de recaída (Guardia et al., 2011).

Tanto los receptores mu como los delta opioides juegan algún papel en la reducción del consumo de alcohol, que producen los antagonistas de los receptores opioides. Los delta podrían actuar en las áreas terminales, facilitando la transmisión dopaminérgica; mientras que los receptores mu podrían modular indirectamente la actividad de las neuronas dopaminérgicas, deprimiendo el tono inhibitorio que ejercen las neuronas GABA sobre las dopaminérgicas, en el ATV (Johnson et al., 1992).

Por otro lado, un paciente que tenga dependencia del alcohol puede presentar síntomas de rebote o abstinencia, cuando lleva unas horas sin ingerir alcohol, y puede obtener un poderoso efecto reforzador negativo de un nuevo consumo de alcohol o de benzodiazepinas, ya que ambos pueden neutralizar, de manera rápida y eficaz, los síntomas de abstinencia (del alcohol). Por tanto, el alcohol puede tener un doble efecto reforzador, el positivo relacionado con la liberación de endorfinas (que van a producir desinhibición de las neuronas dopaminérgicas mesolímbicas) y el negativo, en relación con su capacidad de aliviar la abstinencia del alcohol, así como también determinados síntomas psiquiátricos, como ansiedad, dificultad para conciliar el sueño, fobias, estrés postraumático u otros (Guardia, Surkov y Cardús, 2010).

\section{La adaptación de los receptores kappa al consumo crónico de alcohol}

El consumo de alcohol, igual que el de otras drogas, produce liberación de dopamina en el núcleo accumbens y este sería el trasfondo neurobiológico de su efecto reforzador.

La estimulación de los receptores mu, (que podría ser debida a la liberación de beta-endorfina, inducida por etanol), en el ATV, (lugar de origen de las neuronas dopaminérgicas A10), produce un aumento de la liberación de dopamina; mientras que el bloqueo selectivo del receptor mu resulta en 
una disminución de la liberación de dopamina. Como contrapartida, la estimulación de los receptores kappa, del interior del núcleo accumbens, produce una disminución de la liberación de dopamina, mientras que su bloqueo selectivo produce un marcado incremento de la liberación de dopamina (Spanagel, Herz y Shippenbeerg, 1992).

En situaciones de estrés aumenta la dinorfina en el núcleo central de la amígdala que también co-expresa CRF (factor liberador de corticotropina), lo cual implica una relación de proximidad entre los sitemas kappa opioide y CRF. Además, las neuronas dinorfinérgicas se proyectan hacia las noradrenérgicas del locus cerúleo, una región relacionada con la activación (arousal), la atención y la respuesta al estrés. Los agonistas kappa pueden estimular el eje hipotálamo-hipofisario-suprarrenal y juegan algún papel en la analgesia inducida por el estrés.

En los estados de dependencia de drogas, la inhibición del receptor kappa puede atenuar la ingesta compulsiva de drogas o alcohol, mientras que su activación puede inducir la reinstauración de la conducta de búsqueda de alcohol o drogas, produciendo unos efectos parecidos al estrés.

La activación de los receptores kappa atenúa la liberación de dopamina inducida por el consumo de alcohol y por tanto también su efecto reforzador, mientras que la administración intracerebral de un antagonista de los receptores kappa, la nor-binaltorfimina, produce una disminución de la respuesta operante para etanol, pero sólo en animales que presentan dependencia del alcohol. Por tanto parece que el consumo crónico de alcohol produciría un aumento de la actividad del sistema kappa opioide, que estaría relacionado con un mayor efecto reforzador del alcohol, tras su retirada, lo cual sugiere que los fármacos que modulen el sistema kappa opioide pueden ser eficaces para el tratamiento de la dependencia del alcohol (Shippenberg, Zapata y Chefer, 2007).

Nalmefeno resulta más eficaz que naltrexona para reducir el consumo de alcohol, en las ratas presentan dependencia del alcohol. Ambos fármacos tendrían un efecto parecido sobre los receptores $\mathrm{mu}$, pero nalmefeno tendría además un efecto modulador de los receptores kappa opioides y produciría una mayor reducción del consumo de alcohol que naltrexona, en las ratas dependientes del alcohol (Keating, 2013; Nealey, Smith, Davis y Walker, 2011; Walker y Koob, 2008).

Tanto la activación como la hiperfunción de los receptores kappa opioides produce una reducción en la liberación de dopamina, tanto en el sistema límbico como en el córtex prefrontal, generando un estado de hipodopaminergia e hiperglutamatergia, que cursa con un estado emocional negativo durante la abstención de alcohol y que contribuiría a un mayor efecto reforzador negativo de un nuevo consumo de alcohol. Además esta hipodopaminergia en el córtex prefrontal puede contribuir a una toma de decisiones más impulsiva, un menor control cognitivo de la conducta adictiva y un cierto deterioro de las funciones ejecutivas. Los antagonistas de los receptores kappa reducen la auto-administración de alcohol en las ratas que han desarrollado una dependencia del alcohol y que presentan una hiperfunción del sistema dinoprfina/kappa. (Sirohi, Bakalkin y Walker, 2012).

\section{El Efecto de Deprivación}

En monos que se auto-administran alcohol, tras una deprivación de 2 días se produce un aumento del consumo. Y cuanto más prolongado es el período de deprivación, mayor es el incremento del consumo de alcohol. Kornet, Goosen y Van Ree (1990) lo llamaron fenómeno del "catch-up" o de "recuperar el tiempo perdido" y puede ser revertido por la administración previa de naltrexona (Kornet, Goosen y Van Ree, 1991).

Es un fenómeno parecido al de los pacientes alcohólicos que dejan de beber durante una temporada. El día que prueban a tomar una nueva consumición alcohólica tienen todavía más dificultades que antes, para controlar el consumo de alcohol y este efecto puede ser neutralizado mediante la ingesta previa de naltrexona o nalmefeno (O'Brien, Volpicelli y Volpicelli, 1996).

El fundamento neurobiológico del Efecto de Deprivación es la intensa liberación de dopamina que se produce en el núcleo accumbens y otras estructuras límbicos, en un cerebro adaptado al alcohol, que tiene de base un tono dopaminérgico disminuido (hipodopaminergia). Un nuevo consumo de alcohol va a producir liberación de opioides endógenos, desinhibición de las neuronas dopaminérgicas y un importante aumento del craving y pérdida de control sobre el consumo de alcohol (Clapp et al., 2008; Johnson et al., 1992). No se trata por tanto de un efecto únicamente psicológico sino de un hecho neurobiológico que únicamente se produce en las personas que tienen dependencia del alcohol y que puede ser atenuado o neutralizado por los antagonistas de los receptores opioides.

\section{Los antagonistas de los receptores opioides y la reducción del consumo de alcohol}

El sistema opioide actuaría como mediador de los efectos reforzadores del alcohol que conducirían a su consumo excesivo. Naltrexona y nalmefeno, bloqueando los receptores opioides, evitarían el aumento de la actividad del sistema opioide, tras la ingesta de alcohol y este efecto sería de una relevancia decisiva en los pacientes alcohólicos que prueban a tomar una consumición alcohólica, tras una temporada sin beber alcohol. Su efecto de reducción del valor reforzador del alcohol en estas circunstancias, disminuiría el riesgo de recaída en el consumo excesivo de alcohol (Guardia Serecigni, 2011).

\section{Estudios preclínicos con animales}

Los estudios con animales han comprobado que el alcohol produce un aumento de la liberación de beta-endorfi- 
na, en la pituitaria (Seizinger, Holtz y Herz, 1984). Particularmente en las ratas que "prefieren" alcohol, frente a las ratas control (Froehlich, Zweifel, Harts, Lumeng y Li, 1991). Dicha preferencia, genéticamente determinada y relacionada con el sistema endorfinérgico, parece confirmarse también con respecto a la sensibilidad del sistema encefalinérgico para el alcohol (Li, Li y Froehlic, 1992). En personas con riesgo de alcoholismo, el consumo de alcohol puede producir también un aumento de b-endorfina en el plasma (Gianoulakis et al., 1996).

La naltrexona tiene una preferencia elevada por el receptor mu, intermedia por el kappa y baja por el delta. Los ligandos preferidos del receptor mu son la beta-endorfina y la encefalina, los del receptor delta son la leu- y met-encefalina y los del kappa la dinorfina A y B. Por tanto, aunque la beta-endorfina no es un ligando selectivo, tiene una considerable afinidad para el receptor delta (Terenius, 1996). El nalmefeno tiene un mayor espectro modulador de los receptores opioides, siendo antagonista de los receptores mu y delta, y agonista parcial de los receptores kappa (Keating, 2013; Nealey et al., 2011; Sirohi et al., 2012; Walker et al., 2008).

\section{Estudios de laboratorio con humanos}

En estudios de laboratorio, efectuados en un bar experimental, con personas que presentaban un consumo excesivo de alcohol y que no habían solicitado tratamiento del alcoholismo, naltrexona consiguió una disminución del efecto reforzador positivo del alcohol, de la urgencia por beber, del número de consumiciones tomadas, de la velocidad de consumo de alcohol y un posible incremento de efectos no deseados de la intoxicación alcohólica, tales como cefalea o náuseas, en comparación a placebo (Davidson, Palfai, Bird y Swift, 1999). Es decir, que las personas que tomaron naltrexona notaron que la bebida no les producía el mismo efecto reforzador (ellos decían que no les sabía igual de bien que antes), que bebían a menor velocidad (la consumición alcohólica les duraba más a los que habían tomado naltrexona), el total de consumiciones alcohólicas por sesión era menor, pasaban a tomar otras consumiciones sin alcohol y algunos presentaban una mayor sensación de intoxicación de lo que para ellos era habitual o algunos síntomas desagradables, después de haber tomado varias consumiciones de contenido alcohólico.

Tanto naltrexona (50 mg/día) como nalmefeno (40 mg/ día), consiguieron una reducción del craving, tras un primer consumo de alcohol, del número de consumiciones alcohólicas tomadas, de la elección de una consumición alcohólica (ante la opción de tomar otra sin alcohol) y del efecto euforizante del alcohol (Drobes, Anton, Thomas y Voronin, 2004).

\section{Ensayos clínicos para el tratamiento del alcoholismo}

Cuando un paciente alcohólico consigue reducir su consumo (de alcohol), o bien dejar de beber durante una tem- porada, tiende a recuperarse rápidamente de las consecuencias del alcohol pero los estímulos condicionados pueden disparar estados de "craving" (deseo imperioso de beber) que llevan a un nuevo consumo (de alcohol), tras el cual reaparece la dificultad para controlar o incluso la pérdida de control, que puede llevarle a la recaída. Aunque algunas personas consiguen dejar de beber durante largas temporadas sin ayuda, otros necesitan un tratamiento especializado que reduzca su tendencia hacia la recaída (Work Group on Substance Use Disorders, 2007).

El trasfondo neurobiológico de la dependencia del alcohol son los cambios neuroadaptativos persistentes, inducidos por el consumo excesivo y continuado de alcohol. Sus manifestaciones clínicas son la elevada tolerancia, sensibilización, "craving", dependencia y abstinencia del alcohol. La dependencia se define como la necesidad de continuar tomando la sustancia para evitar el síndrome de abstinencia, pero la diferenciación tradicional entre dependencia física y psicológica es artificial, ya que ambas tienen que ver con una disfunción de determinadas estructuras del Sistema Nervioso Central (Guardia et al., 2010; Nestler, Hope y Widnell, 1993).

Los antagonistas de los receptores opioides, como naltrexona y nalmefeno, producen una reducción del consumo de alcohol, tanto en animales (Froehlic y Li, 1993), como en bebedores sociales en una situación de bar experimental (Davidson et al., 1999; Drobes et al., 2004), como en pacientes alcohólicos en recuperación; resultando por tanto de gran utilidad para la prevención de recaídas. (Anton et al., 2006; Guardia, Caso, Arias, Gual, Sanahuja et al., 2002; O'Malley, Jaffe, Chang, Scottenfeld, Meyer et al., 1992; Volpicelli, Alterman, Hayashida y O'Brien, 1992).

Los ensayos clínicos controlados para de tratamiento del alcoholismo han comprobado que los antagonistas de los receptores opioides producen una disminución de los efectos reforzadores o euforizantes del consumo de alcohol, una disminución del "craving”, una mejor capacidad de control, tras una primera consumición o incluso un cierto efecto aversivo del consumo de alcohol (Swift, WhelihanKuznetson, Buongiorno y Hsuing, 1994; Volpicelli, Watson, King, Sherman y O'Brien, 1995;).

El efecto esperado es por tanto mejorar el auto-control del paciente sobre consumo de alcohol y, a largo plazo, se puede producir incluso un proceso de extinción del condicionamiento adictivo, recuperando progresivamente su libertad en la toma de decisiones y remitiendo su obsesión por la bebida (Guardia Serecigni, 2011).

El estudio COMBINE, efectuado en Estado Unidos (Anton et al., 2006), compara diversas modalidades de tratamiento farmacológico y psico-social del alcoholismo y concluye que uno de los indicadores más útiles para evaluar los resultados del tratamiento es el número de días de consumo excesivo ("heavy drinking days"), ya que este indicador tiene una buena correlación con la cantidad de consecuencias negativas 
que sufre el paciente a lo largo del tratamiento (como consecuencia del consumo excesivo de alcohol) (Falk, Wang, Liu, Fertig, Mattnson et al., 2010). Esta correlación sugiere que si un paciente consigue mantener un consumo de alcohol que no alcance las 5 consumiciones en un día (si es un hombre), 4 si es una mujer, presentaría pocas o ninguna consecuencia negativa, igual que la persona que se ha mantenido sin tomar bebidas alcohólicas. Es decir que un consumo ocasional de bajo riesgo conseguiría los mismos resultados favorables que la abstención completa y continuada.

Dicho de otra manera, no beber alcohol todos los días y no alcanzar el límite del consumo excesivo de alcohol en ninguna de las ocasiones de beber, se podría considerar también como remisión clínica ya que no estaría asociado a consecuencias negativas. Por tanto, el objetivo de tratamiento basado en la reducción del consumo de alcohol puede ser tan satisfactorio como la abstención continuada, siempre que el paciente no exceda los límites del consumo de bajo riesgo en ninguna de las ocasiones de beber.

En el estudio COMBINE, naltrexona oral a dosis de 100 $\mathrm{mg}$ /día, durante 16 semanas, consigue un aumento del porcentaje de días de abstención $(80,6 \%$ vs. $75,1 \%)$ y una reducción del riesgo de días de consumo excesivo de alcohol (66,2\% vs. $73,1 \%)$, en comparación con placebo. Además se utilizó el criterio que denominan "buen resultado clínico" y que definen como no más de 2 días de consumo excesivo de alcohol a la semana, un consumo máximo de 14 consumiciones/semana para los hombres (11 para las mujeres) y la ausencia de problemas significativos, relacionados con el alcohol, durante las últimas 8 semanas de las 16 totales de tratamiento (Anton et al., 2006; Anton, 2008).

Los pacientes que bebieron durante el estudio COMBINE presentaban una menor gravedad y una mayor probabilidad de tener un objetivo personal de consumo controlado. Además, el efecto terapéutico de naltrexona no alcanzó la significación estadística hasta el segundo mes de tratamiento, en diversos estudios (Anton et al., 2006; Bouza, Magro, Muñoz y Amate, 2004; Guardia et al., 2002), lo cual sugiere que su efecto podría ser progresivo y que no se pondría claramente de manifiesto hasta que el paciente no efectúa sus primeros consumos de alcohol.

Los primeros ensayos clínicos con nalmefeno se orientaron, igual que los de naltrexona, hacia el objetivo de abstención de bebidas alcohólicas, pero señalaron algunas ventajas en comparación a naltrexona, tales como que no presenta una asociación dosis-dependiente con respecto al riesgo de toxicidad hepática, tiene una mayor biodisponibilidad y su efecto antagonista de los receptores opioides resulta más competitivo y tiene una duración más prolongada. Nalmefeno, tomado diariamente, resultó eficaz para la prevención de recaídas hacia el consumo excesivo de alcohol en la mayoría de los estudios (Karhuvaara, Simojoki, Virta, Rosberg, Loyttiniemi et al., 2007; Mason, ritvo, Morgan, Salvato, goldberg et al., 1994; Mason, Salvato, Williams, Ritvo y Cutler,
1999), pero no resultó superior a placebo en el estudio de Anton, Pettinati, Zweben, Kranzler, Johnson et al. (2004).

Posteriormente, el estudio de Karhuvaara et al. (2007) dio paso a un nuevo procedimiento llamado "targeted", en el que personas que presentaban un consumo excesivo de alcohol fueron instruidas para tomar nalmefeno cuando ellos consideraran que el consumo de alcohol era inminente. Y dicho procedimiento asociado a un simple "manejo médico" consiguió una reducción significativa del consumo excesivo de alcohol, en comparación al placebo. Otro estudio de nalmefeno "targeted" concluyó que las variaciones polimórficas en los genes de los receptores opioides no modifican la respuesta del tratamiento con nalmefeno, a diferencia de lo que sucede en el tratamiento con naltrexona, en el cual el polimorfismo ASN40ASP del receptor mu OPRM1 modera la respuesta del tratamiento con naltrexona (Arias, Armeli, Glernter, Covault, Kallio et al., 2008)

\section{Farmacología de naltrexona y nalmefeno}

Los estudios efectuados con naltrexona han confirmado su eficacia para reducir el consumo de alcohol y la tasa de recaídas, a los 3 meses de tratamiento del alcoholismo (Anton et al., 2006; Bouza et al., 2004; Pettinati, O'Brien, Rabinowitz, Wortman, Oslin et al., 2006; Srisurapanont y Jarusuraisin, 2005). Los metanálisis de Cochrane han confirmado que naltrexona (50 mg/día, durante 12 semanas), consigue una reducción del $36 \%$ en la tasa de recaídas y reduce el número de días de: consumo de alcohol, consumo excesivo (de alcohol), consumo total (de alcohol), craving (de alcohol) y los niveles de gamma-glutamiltransferasa. Sin embargo, el tamaño del efecto ha sido considerado como pequeño a moderado (Kranzler, Modesto-Lowe y Van Kirk, 2000; Rösner, Hackl,-Herrweth, Leucht, Vecchi, Srisurapanant et al., 2010).

En algunos estudios controlados, naltrexona no ha demostrado ser superior a placebo, con el objetivo de prevenir la recaída en el consumo excesivo de alcohol (Gueorguieva, Wu, Pittman, Cramer, rosenheck et al., 2007; Krystal, , Cramer, Krol, Kirk y Rosenheck, 2001; Oslin, Lynch, Pettinati, Kampmann, Gariti et al., 2008;), sin embargo, un reanálisis de dos estudios negativos sugiere que naltrexona puede reducir el riesgo de un consumo excesivo y que aumenta la probabilidad de abstención de alcohol (Chick, Anton, Checinski, Croop, Drummond et al., 2000).

Un buen cumplimiento en la toma de medicación puede ser decisivo para que la reducción de la tasa de recaídas o del craving alcancen la significación estadística, en comparación con placebo (Anton, 2008). Por tanto, es posible que la eficacia de naltrexona aumente si su administración es supervisada por una familiar o por la enfermera, en cuyo caso se puede hacer además un seguimiento intensivo del paciente, con determinaciones periódicas de sustancias en la orina (Guardia Serecigni et al., 2008). 
La naltrexona inyectable de liberación prolongada se administra en dosis de $380 \mathrm{mg}$ cada cuatro semanas y produce una reducción de los días de consumo excesivo de alcohol en un $25 \%$ y de las consumiciones tomadas los días en los que el paciente vuelve a beber. El inicio del efecto terapéutico podría ser muy rápido (desde el segundo día) y se mantendría a lo largo de todo el tratamiento, con lo cual podría facilitar el compromiso del paciente con el tratamiento y la intervención psicoterapéutica especializada (Ciraulo, Dong, Silverman, Gastfried y Pettinati, 2008; Garbutt, Kranzler, O'Malley, Gastfriend, Pettinati et al., 2005). Un estudio efectuado con 624 pacientes ha comprobado que naltrexona de liberación prolongada no tuvo efectos hepatotóxicos, ni siquiera para los pacientes que siguieron bebiendo alcohol en exceso durante el tratamiento, consiguiendo una reducción de la GGT superior al placebo en las semanas 4, 8,12 y 20 de tratamiento (Lucey, Silverman, Illeperuma y O'Brien, 2008).

\section{Farmacocinética y Farmacodinámica}

La naltrexona es un derivado ciclopropílico de la oximorfona, estructuralmente similar a la naloxona y nalorfna. Por vía oral, se absorbe rápidamente y casi por completo (95\%). Alcanza la concentración máxima en 1 hora y circula unida a proteínas plasmáticas en un $21 \%$. Su vida media es de 3'9 horas (llegando a 9'7 horas, tras su administración crónica), sus niveles disminuyen a lo largo de las primeras 24 horas. Sufre un intenso metabolismo hepático de primer paso, a través del sistema citosol, mediado por las 3 hidrodiol-deshidrogenasas. Aproximadamente un $95 \%$ de la naltrexona absorbida es metabolizada y convertida en su metabolito activo principal, 6-beta-naltrexol, un antagonista opioide puro, que tiene una vida media más prolongada que la naltrexona (12'9 horas), lo cual facilita que su acción sea más duradera. Se elimina principalmente por vía renal. El estado de equilibrio se alcanza rápidamente y el fármaco no se acumula.

Se considera que naltrexona actúa como antagonista competitivo de los receptores mu, delta y kappa opioides, con una mayor afinidad por el receptor mu (Ortiz Camúñez, 1996). La administración de $50 \mathrm{mg}$ produce un bloqueo de los receptores opioides durante 24 horas. En estudios de tratamiento a largo plazo (21 meses) no parece que se desarrolle tolerancia para las propiedades antagonistas opioides de la naltrexona (González y Brogden, 1988).

Nalmefeno tiene un efecto agonista parcial sobre los receptores kappa opioides, pero ante un sistema de receptores kappa que presenta regulación ascendente, como consecuencia del consumo crónico de alcohol, actúa como una antagonista funcional (Keating, 2013; Kisler, Sirohhi, Reis, Jansen, Quock et al., 2013). Este perfil receptorial de nalmefeno ha sido relacionado con su mayor eficacia que naltrexona para la reducción del consumo de alcohol, en ratas que presentan dependencia del alcohol (Walker et al., 2008)
La dosis terapéutica recomendada es de 50 milígramos al día para naltrexona y $18 \mathrm{mg} /$ día para nalmenfeno. Los primeros días de tratamiento puede ser recomendable administrar sólo $25 \mathrm{mg}$ /día para reducir posibles efectos adversos de naltrexona, sin embargo el estudio COMBINE y algún otro estudio efectuado en Estados Unidos han a utilizado dosis de $100 \mathrm{mg}$ /día, durante 16 semanas de tratamiento (Anton et al., 2006; Anton, 2008) .

Nalmefeno tiene un radical metileno $(\mathrm{C}=\mathrm{CH} 2)$ sustituido por un grupo cetónico $(\mathrm{C}=\mathrm{O})$ en su posición 6 , con respecto a naltrexona y, en comparación con naltrexona tiene una mayor biodisponibilidad (40-50\%), una vida media más prolongada y una mayor afinidad para los receptores delta y kappa opioides.

Nalmefeno se absorbe rápidamente, alcanza su concentración plasmática más elevada a las 2-3 horas y no modifica el intervalo QTc, ni la morfología de la onda T del electrocardiograma. Por tanto no altera el ritmo cardíaco ni requiere monitorización del QTc en la práctica clínica (Matz, Graff, Vainio, Kaillio, Hojer et al., 2011). Tiene una vida media de 13,4 horas y una farmacocinética lineal. A las dos horas, la ocupación del receptor mu es del $93 \%$ al $100 \%$ y se mantiene elevada más allá de las 24 horas, al mismo tiempo que su concentración plasmática disminuye progresivamente, lo cual sugiere una lenta disociación del receptor mu-opioide. $\mathrm{Su}$ prolongada ocupación de receptores mu opioides, tras su administración aislada o repetida, resulta muy apropiada para su administración no diaria (Ingman, Hagelberg, Aalato, Nagren, Juhakoski et al., 2005; Niciu y Arias, 2013).

Se considera que los metabolitos de nalmefeno no contribuyen de manera significativa a su efecto farmacológico. Nalmefeno es extensa y rápidamente metabolizado por glucurono-conjugación y su eliminación se produce por vía renal. Mientras que naltrexona se metaboliza por vías oxidativas, nalmefeno se metaboliza primariamente por vías glucuronoconjugación y no presenta hepatotoxicidad dosis-dependiente, lo cual mejora su perfil de seguridad en pacientes con disfunción hepática (Salvato y Mason, 1994; Niciu y Arias, 2013).

Los efectos adversos de naltrexona pueden afectar al $30 \%$ de los pacientes, siendo náuseas y cefalea los más frecuentes y con menor frecuencia, mareo, vómito, dolor o malestar abdominal, anorexia, astenia, inquietud, insomnio o ansiedad, que pueden aparecer los primeros días de tratamiento, suelen ser de intensidad leve y tienden a desaparecer (Croop, Faulkner y Labriola, 1997). El inicio del tratamiento con una dosis menor ( $25 \mathrm{mg} /$ día) y, acompañada por la comida, puede minimizar los efectos adversos y favorecer la adaptación progresiva del organismo, para llegar a alcanzar unos días después la dosis habitual de $50 \mathrm{mg}$ /día.

Entre los posibles efectos adversos de nalmefeno, los más frecuentes son mareo, náuseas y trastorno del sueño. Otros síntomas menos frecuentes son sequedad de boca, cefalea, taquicardia-palpitaciones, sudoración, espasmos muscula- 
res, anorexia, pérdida de peso, astenia. La mayoría de ellos son ligeros o moderados, aparecen al inicio del tratamiento y son de corta duración. Excepcionalmente se han descrito estados confusionales y de manera excepcional alucinaciones o síntomas disociativos. La mayoría de los efectos adversos tienden a su remisión sin necesidad de modificar el tratamiento y no reaparecen con una nueva administración.

Nalmefeno no modifica el intérvalo QTc ni la morfología de la onda T del electrocardiograma (Keating, 2013) y durante su tratamiento en los estudios ESENSE no se han producido cambios clínicamente relevantes o diferencias entre nalmefeno y placebo, con respecto a signos vitales, análisis de laboratorio, peso corporal, registros electrocardiográficos y puntuación de la escala "Profile Mood States" que evalúa posibles síntomas emocionales (Gual, He, Torup, van den Brink y Mann, 2013; Keating, 2013; Mann, Bladstrom, Torup, Gual y van den Brink, 2013).

\section{Tolerabilidad y Seguridad}

Naltrexona, a dosis de $50 \mathrm{mg} /$ día, es un fármaco bien tolerado y que tiene pocos efectos adversos, particularmente cuando el paciente no presenta un consumo elevado de bebidas alcohólicas. Los pacientes alcohólicos, tratados con naltrexona durante 12 semanas tienen a presentar una mejoría de sus enzimas hepáticos. Los posibles efectos secundarios tienden a remitir en 7 a 14 días y pueden ser minimizados iniciando el tratamiento con $25 \mathrm{mg}$ al día, durante la primera semana.

Naltrexona no produce aumento sino disminución de determinados enzimas hepáticos, como la gamma-glutamiltransferasa (GGT) y la aspartato-aminotransferasa (AST); mientras que en el grupo control también se produce una disminución de GGT pero no de AST. Al finalizar el tratamiento no se han encontrado diferencias significativas, en cuanto a los niveles de GGT y AST, entre los grupos experimental y control, al compararlos con los niveles basales de dichos enzimas hepáticos (Croop et al., 1997; Guardia et al., 2002; O’Brien et al., 1996). En un estudio piloto, efectuado con pacientes obesos que recibieron dosis seis veces mayores a la habitual (300 mg/día), se detectó una elevación de las transaminasas, debido a lesión hepatocelular, que remitió al retirar la naltrexona.

Los estudios ESENSE han confirmado que el tratamiento con nalmefeno se asocia a una reducción de los enzimas hepáticos alanina-aminotransferasa (ALT) y gamma-glutamiltransferasa (GGT), significativamente mayor que en los pacientes que tomaron placebo (Mann et al., 2013; Gual et al., 2013).

\section{Indicaciones y Contraindicaciones}

Antes de la prescripción de naltrexona o nalmenfeno, conviene descartar el consumo de opiáceos ya que ambos fármacos antagonizan sus posibles efectos terapéuticos y desencadenarían un grave síndrome de abstinencia en las personas que han desarrollado una dependencia de opiáceos. Y cuando el paciente vaya a ser intervenido quirúrgicamente, tendrá que dejar de tomar naltrexona o nalmefeno de tres a siete días antes de la intervención, particularmente cuando se trata de cirugía mayor (Anton, 2008).

Conviene tener en cuenta los antecedentes de hepatopatía y los fármacos asociados que tengan algún potencial hepatotóxico. En los análisis previos al inicio del tratamiento conviene solicitar indicadores de funcionalismo hepático y renal, hemograma completo, test de embarazo (en mujeres en edad fértil) y detección de opiáceos y otras sustancias en la orina.

Debido a su posible efecto hepatotóxico, naltrexona está contraindicada en el embarazo, lactancia, hepatitis aguda, insuficiencia hepática, lesión hepatocelular, consumo reciente de opiáceos, dependencia activa de heroína u otros opiáceos, síntomas de abstinencia de opiáceos, abstinencia aguda del alcohol y pacientes que requieren analgésicos, antitusígenos o antidiarreicos, de tipo opioide (González et al., 1988; Ortiz Camuñez, 1996). En pacientes con hepatitis aguda, insuficiencia hepática o grave afectación hepatocelular, reflejada por una elevación de los enzimas hepáticos, 3 veces superior al límite normal y/o de la bilirrubinemia, se deberían adoptar precauciones si presentan una disfunción hepática menos grave o que tengan antecedentes de hepatopatía reciente (Berg, Pettinati y Volpicelly, 1996).

Las contraindicaciones de nalmefeno son el embarazo, lactancia, un grave deterioro de la función hepática o renal, consumo reciente de opiáceos, dependencia de heroína u otros opiáceos, síntomas de abstinencia de opiáceos, abstinencia aguda del alcohol, pacientes que requieren analgésicos, antitusígenos o antidiarreicos, de tipo opioide (Keating, 2013; European Medicines Agency, 2013).

Se recomienda interrumpir el tratamiento con nalmefeno un semana antes de intervenciones quirúrgicas que puedan requerir la administración de analgésico opiáceos. Conviene tener precaución en los pacientes que presentan transaminasas (ASAT y ALAT) más de 3 veces por encima del límite superior normal y monitorizar la función hepática o renal de los que presentan un deterioro de dicha función hepática o renal. Dado que los estudios con animales han demostrado su potencial toxicidad reproductiva, se recomienda no tomar nalmefeno durante el embarazo ni durante la lactancia, dado que se excreta por la leche, aunque conviene sopesar posibles ventajas de su tratamiento, si existe una experiencia previa de evolución favorable con nalmefeno y la paciente presenta un consumo excesivo de alcohol durante la lactancia.

\section{Posibles interacciones}

Naltrexona presenta un bajo nivel de interacciones, debido a que su metabolismo hepático está a cargo del sistema citosólico y no del sistema del citocromo P450. Algunos autores consideran que podría administrarse asociada a disulfiram y a otras medicaciones psicotrópicas, a sus dosis 
habituales, teniendo sólo en cuenta que conviene monitorizar periódicamente la función hepática (Berg et al., 1996).

Nalmefeno se metaboliza por los enzimas CYP450 y UGT. El tratamiento a largo plazo simultáneo con potentes inhibidores del enzima UGT2B7, (como diclofenaco, fluconazol, medroxiprogesterona o ácido meclofenámico), puede incrementar la exposición al nalmefeno. Por otro lado, el tratamienhto simultáneo con inductores del enzima UGT (como dexametasona, fenobarbital, rifampicina u omeprazol) pueden disminuir la eficacia de nalmefeno debido a una disminución de sus concentraciones plasmáticas.

Tanto naltrexona como nalmefeno impiden el efecto analgésico, antitusígeno o antidiarreico de los fármacos opiáceos que han sido prescritos con esta finalidad y pueden desencadenar un grave síndrome de abstinencia de opiáceos en personas que tienen una dependencia activa de heroína, metadona, buprenorfina u otros opiáceos.

No se produce una interacción farmacocinética clínicamente significativa nalmefeno y alcohol, de manera que nalmefeno no aumenta ni tampoco disminuye la intoxicación por el alcohol.

\section{Características diferenciales de nalmefeno}

Nalmefeno ha sido considerado un modulador del sistema opioide. Actúa como antagonista de los receptores mu y delta (opioides), y agonista parcial de los receptores kappa, pero algunos autores proponen que ante un estado de regulación ascendente de los receptores kappa podría actuar como antagonista (Keating, 2013). Comparado con naltrexona, presenta una mayor afinidad para los receptores delta y kappa, una mayor biodisponibilidad, una vida media más larga y, por tanto, un efecto más prolongado. Además, no se han encontrado indicios de hepatotoxicidad dosis-dependiente (Nutt, 2014).

Algunos autores afirman que nalmefeno es más eficaz que naltrexona, para reducir el consumo de alcohol, cuando el organismo ha desarrollado una dependencia del alcohol, debido a su efecto diferencial sobre los receptores kappa opioides (Walker et al., 2008; Walker, Zorrilla y Koob, 2011). La ingesta crónica de alcohol conduce a una regulación ascendente del sistema dinorfina/kappa opioide, en la persona que ha desarrollado dependencia del alcohol, que estaría asociado a un estado de hipodopaminergia el cual ha sido relacionado con niveles más elevados de craving. Nalmefeno podría renormalizar dicho estado de hipodopaminergia y, por lo tanto, reducir también el craving de alcohol (Spanagel y Vengeliene, 2012)

Con el objetivo de abstención continuada, nalmefeno ha resultado eficaz para prevenir recaídas, en algunos ensayos clínicos (Mason et al., 1994; 1999), pero uno de ellos no ha podido confirmar su eficacia (Anton et al., 2004). Con el nuevo objetivo de reducción del consumo de alcohol, algunos estudios piloto apuntaron a que naltrexona y nalmefeno podrían ser de utilidad, ya que producían una dis- minución del número de días en que la persona tomaba alcohol, el número de consumiciones tomadas por ocasión, el número de días de consumo excesivo de alcohol y las cifras de los marcadores biológicos ALT y GGT (Heinala, Alho, Kiianmaa, Lonquist y Sinclair, 2001; Hernández-Avila, Song, Kou, Tennen, Armeli et al., 2006; Kranzler, Tennen, Armeli, Chan, Covault et al., 2009).

La eficacia de nalmefeno, con un nuevo objetivo de tratamiento, la reducción del consumo de alcohol, ha sido evaluada a partir de tres estudios multicéntricos, controlados con placebo y efectuados en Europa con un nuevo procedimiento en el que el paciente alcohólico toma un comprimido de $18 \mathrm{mg}$ de nalmefeno únicamente el día que se enfrenta a un consumo de alcohol o bien a alguna situación de riesgo de recaída.

A partir de los resultados de los estudios ESENSE 1 y 2 (Gual et al., 2013; Mann et al., 2013), se confirma la indicación de nalmefeno para la reducción del consumo de alcohol en personas que presentan dependencia del alcohol y la Agencia Europea de Medicamentos ha aprobado esta nueva indicación en 2013.

\section{Un nuevo objetivo en el tratamiento del alcoholismo}

El tratamiento con nalmefeno produce una reducción del consumo de alcohol. No beber alcohol todos los días y beber menos cantidad por ocasión, es un objetivo realista para un paciente alcohólico de baja gravedad, si toma nalmefeno. Sobretodo si el paciente está motivado y comprometido para reducir su consumo de alcohol.

Por tanto, las personas que presentan dificultad para controlar el consumo de alcohol, que ya han sufrido alguna de sus consecuencias negativas y que reconocen la necesidad de reducir su consumo de alcohol, pueden beneficiarse del tratamiento con nalmefeno.

El perfil del paciente ideal sería probablemente el de una persona de mediana edad, que tiene una dependencia (del alcohol) de baja gravedad, que no presenta un claro síndrome de abstinencia del alcohol, que es la primera vez que solicita tratamiento del alcoholismo, que no tiene una grave comorbilidad médica, psiquiátrica, ni adictiva y que se propone conseguir una reducción sustancial de su consumo de alcohol. Si además tiene una buena estabilidad familiar, social y laboral, también son factores que favorecen los resultados del tratamiento (Van Amsterdam y Van den Brink, 2013).

El consumo excesivo de alcohol suele estar asociado a consecuencias negativas. La mayoría de las personas que sufren dichas consecuencias negativas no presentan un trastorno por consumo de alcohol. Podríamos decir que tienen esa costumbre pero que pueden modificarla si lo desean ya que todavía no han desarrollado una adicción. Por tanto, estas personas pueden reducir su consumo cuando se lo proponen seriamente y no requieren un tratamiento especializado. 
Cuando una persona ha desarrollado una adicción al alcohol es poco probable que pueda reducir y mantener un bajo consumo de alcohol de manera efectiva y sostenida en el tiempo. La dificultad para controlar el consumo de alcohol, sobretodo tras el primer consumo, sería precisamente el síntoma cardinal de la adicción al alcohol y los antagonistas de los receptores opioides neutralizarían dicho síntoma. El esfuerzo por reducir su consumo (de alcohol) es una condición necesaria pero no suficiente. Nalmefeno ayuda a que la persona que se propone reducir el consumo de alcohol pueda llegar a conseguirlo. El tratamiento del alcoholismo con nalmefeno consigue algo parecido al modelo médico de tratamiento de enfermedades, en el cual un fármaco específico neutraliza un determinado síntoma. En la persona que sufre alcoholismo el síntoma es conductual, es la dificultad para controlar o pérdida de control.

\section{Nalmefeno para la reducción del consumo de alcohol}

Los estudios ESENSE se han efectuado con pacientes que presentaban un trastorno por dependencia del alcohol de baja a moderada gravedad, es decir, que no presentaban un síndrome de abstinencia del alcohol (que no superaban los 10 puntos de la escala CIWA), y que no tenían una importante comorbilidad médica, adictiva, ni psiquiátrica. Se trataba por tanto de pacientes que no requerían un tratamiento de desintoxicación del alcohol y que podían iniciar el tratamiento nalmefeno, en régimen ambulatorio y sin dejar de tomar bebidas alcohólicas.

En cada una de las visitas se utilizó el procedimiento de intervención motivacional y psicoeducativa, para favorecer la adherencia al tratamiento, conocido como BRENDA, un acrónimo que resulta de las 6 acciones sucesivas que se pueden hacer en cada una de la visitas con el paciente, como son una evaluación biopsicosocial, devolución al paciente de la evaluación inicial, comprensión empática de su respuesta, identificación de las necesidades y preferencias del paciente, consejo directo (al paciente) sobre el procedimiento para resolver sus necesidades, evaluar la reacción del paciente ante el consejo del médico y adaptación del profesional a las preferencias del paciente, para llegar finalmente a consensuar con él los objetivos futuros (Volpicelli, Pettinati, McLellan y O'Brien, 2001).

Con la finalidad de introducir el nuevo procedimiento "as needed", que se podría traducir como "si precisa" o "a demanda", el paciente recibió la instrucción de tomar un comprimido de nalmefeno de $20 \mathrm{mg}$, sólo los días en los cuales tiene la intención de tomar alguna bebida alcohólica o bien ante situaciones en las que es probable que tome alguna consumición de contenido alcohólico y se le recomienda que, si le es posible, tome el comprimido una hora antes del inicio del consumo de alcohol y si no, que lo haga lo antes posible, incluso junto con el inicio del consumo de alcohol.
Los pacientes de los estudios ESENSE tomaron nalmefeno (o placebo) durante 6 meses, de manera aleatorizada y en régimen "doble ciego". El estudio ESENSE 1 se desarrolló en países del norte y el ESENSE 2 en países del sur de Europa. Los objetivos del tratamiento fueron el cambio desde el inicio al mes 6 en el número de días de consumo excesivo de alcohol ("heavy drinking days") y el promedio de consumo de alcohol por ocasión ("total alcohol consumption"). Los pacientes que tenían asignado el principio activo, lo tomaron el $48 \%$ y $57 \%$ de los días, mientras que los que fueron asignados a placebo lo hicieron en el 63,9\% y $65,2 \%$ de los días, en los estudios ESENSE 1 y 2 , respectivamente.

Entre la entrevista de selección y la de aleatorización, una elevada proporción de pacientes (18\% del ESENSE 1 y $33 \%$ del ESENSE 2) ya habían disminuido su consumo de alcohol por debajo de los 6 días de consumo excesivo de alcohol, durante las 4 semanas previas, o por debajo del nivel medio de riesgo de consumo de alcohol, que eran criterios necesarios para la inclusión en el estudio y que habían sido confirmados en la entrevista de selección.

Siguiendo el mencionado procedimiento, nalmefeno produjo una reducción del número de días de consumo excesivo de alcohol, significativamente mayor que el placebo, en ambos estudios ESENSE y también del consumo total de alcohol en el estudio ESENSE 1, pero no en el ESENSE 2.

Se definió el concepto de RESPUESTA al tratamiento como una reducción desde un muy elevado nivel de riesgo de consumo de alcohol hasta un nivel medio o inferior, o también desde un nivel alto o medio hasta un nivel de consumo de bajo riesgo. Lógicamente, los pacientes que hicieron una importante reducción del consumo (de alcohol), entre la visita de selección y la de inicio del tratamiento, ya no podían reducir más su consumo de alcohol a lo largo del tratamiento, es decir, iniciaron el tratamiento con un nivel de consumo de riesgo bajo y se mantuvieron en este nivel a lo largo del tratamiento. Sin embargo, el subanálisis del grupo de pacientes que al iniciar el tratamiento seguían presentando un consumo de riesgo alto (>60 gr/día para los hombres y $>40$ gr/día para las mujeres) confirmó la eficacia de nalmefeno para la reducción del consumo de alcohol, ya que las diferencias con el placebo fueron significativas a favor de nalmefeno.

Además, los que tomaron nalmefeno presentaron una mayor reducción en la puntuación de las escalas de impresión clínica global, tanto la de gravedad como la de mejoría, y también en los niveles de ALT y GGT, con diferencias significativas a favor de nalmefeno.

En un tercer estudio llamado SENSE, en el que el tratamiento con nalmefeno se prolongó durante 12 meses, se siguió el mismo procedimiento para evaluar seguridad, tolerabilidad y eficacia de nalmefeno en pacientes con dependencia del alcohol. El 39\% de los pacientes presentó una reducción sustancial de su consumo de alcohol entre la visita de selección y la de inicio de tratamiento. La retención a 
los 12 meses fue del $63 \%$ y la reducción, tanto de los días de consumo excesivo de alcohol como del consumo total de alcohol, resultó significativamente mayor con nalmefeno que con placebo, (a los 12 meses de tratamiento), como también lo fueron la reducción en la puntuación de las escalas de impresión clínica global (de gravedad y de mejoría) y de ALT y GGT. (Van den Brink, Aubin, Bladström, Torup, Gual et al., 2013; Van den Brink, Sorensen, Torup, Mann y Gual, 2014).

El análisis del subgrupo de los que seguían presentando un consumo de alto riesgo, al inicio del tratamiento con nalmefeno, confirma una satisfactoria tasa de respuesta del $72 \%$ de los que tomaron nalmefeno, en comparación al $57 \%$ de los que tomaron placebo, al finalizar el tratamiento.

Nalmefeno fue bien tolerado y los efectos adversos que aparecieron con mayor frecuencia $(>5 \%)$ fueron: mareo, náuseas, cefalea, insomnio, vómito, fatiga y disminución del apetito. Otros menos frecuentes fueron: hiperhidrosis, somnolencia, taquicardia, nasofaringitas y trastorno del sueño.

Los efectos adversos aparecieron desde el primer día de tratamiento (con nalmefeno), la mayoría fueron pasajeros (3-7 días) y de una gravedad ligera a moderada (Van den Brink et al., 2013; 2014). Los que llevaron con mayor frecuencia al abandono del tratamiento fueron: mareo, náuseas, fatiga y cefalea. Al comparar los efectos adversos graves que aparecieron en los pacientes que tomaban nalmefeno o placebo, se detectaron respectivamente un $5,9 \%$ frente al $6,7 \%$ en el estudio ESENSE 1; un 2,2\% frente al 4,7\% en el ESENSE 2; y un 6,9\% frente al 5,4\% en el estudio SENSE; llegando a la conclusión que la mayoría de efectos adversos graves no podían ser atribuidos a nalmefeno sino más bien a la propia patología de los pacientes, debido a que los pacientes no dejaban de beber durante el tratamiento con nalmefeno y también a que el procedimiento de recogida consiste en que cualquier síntoma que el paciente refiera -en cada una de las visitas- se registra como posible efecto adverso, independientemente de que pueda o no ser luego atribuido al fármaco en estudio (Keating, 2013).

Un estado confusional o síntomas alucinatorios o disociativos, aparecieron sólo de manera excepcional, sólo al inicio del tratamiento, fueron de gravedad ligera o moderada, de corta duración y no se volvieron a presentar con la administración repetida de nalmefeno (European Medicines Agency, 2013).

\section{Ventajas del tratamiento con nalmefeno para la reducción del consumo de alcohol}

El tratamiento con nalmefeno es seguro, bien tolerado y sencillo. Produce una reducción de los días de consumo excesivo de alcohol y de la cantidad de alcohol tomada por ocasión, en los pacientes con dependencia del alcohol (Gual et al., 2013; Mann et al., 2013).

La reducción del consumo de alcohol se asocia a una disminución del número de accidentes, conductas hostiles o auto-destructivas y alteraciones del ritmo cardíaco (Rehm,
Baulinas, Borges, Graham, Irving et al., 2012). El estudio COMBINE ya detectó una disminución de las consecuencias negativas en paralelo con la reducción del consumo de alcohol, de tal manera que los pacientes que no tuvieron ningún día de consumo excesivo, tampoco presentaron las consecuencias negativas que suelen estar asociadas (Anton et al., 2006; Falk et al., 2010).

El objetivo de reducción, en comparación con el de abstención continuada, tiene la ventaja de adaptarse mejor a la demanda de ayuda del paciente alcohólico. Con frecuencia el paciente refiere que su objetivo es dejar de beber, pero también con la misma frecuencia, el paciente espera que más adelante, algún día tomará alguna consumición alcohólica. Es decir, la expectativa del paciente, y con frecuencia también la de sus familiares, es que tras una temporada de abstención, el problema se habrá resuelto y él habrá recuperado el control sobre el consumo de alcohol, ya que ellos creen que el control es voluntario y depende exclusivamente de que el paciente se esfuerce un poco más para llegar a conseguirlo.

Desafortunadamente, la realidad es que tras una temporada sin beber alcohol, y debido al efecto de deprivación, el día que pruebe una nueva consumición alcohólica, lo más probable es que se descontrole con la bebida.

Por otro lado, los pacientes que tienen la expectativa de que más adelante podrán tomar alguna consumición alcohólica sin problemas, no van a aceptar un objetivo de abstención completa y continuada, y rechazarán la toma de fármacos que les impiden algún consumo de alcohol ocasional. Algunos pacientes rechazarán el tratamiento del alcoholismo, si la condición es que tienen que dejar de beber por completo.

El tratamiento con nalmefeno orientado a la reducción del consumo de alcohol se adapta mejor a la demanda de la mayoría de los pacientes que inician el tratamiento del alcoholismo. Puede favorecer la aceptación, la adherencia, la retención en el programa de tratamiento y el compromiso con este nuevo objetivo terapéutico, la reducción del consumo de alcohol.

Para los pacientes puede resultar difícil de comprender: (1) que el control sobre el consumo de alcohol sea una función del Sistema Nervioso y que no se encuentre sometido a la propia voluntad del paciente (2) que dicho control dependa del buen funcionamiento de determinadas estructuras cerebrales (3) que interviniendo sobre los receptores opioides se pueda renormalizar el control sobre la bebida y (4) que un simple comprimido pueda conseguirlo. El estudio COMBINE ha comprobado que, tanto naltrexona $(100 \mathrm{mg} /$ día $)$ como la terapia cognitivo-conductual consiguen una mayor eficacia que el placebo. Sin embargo, la asociación de ambas no consigue mejores resultados que naltrexona, simplemente acompañada del llamado "manejo médico", es decir que para obtener el mayor beneficio terapéutico de naltrexona no es necesaria una intervención psicológica (Anton et al., 2006). 
En los estudios ESENSE, efectuados con nalmefeno, se ha utilizado una pequeña intervención motivacional para optimizar el manejo y el cumplimiento de la medicación, el llamado procedimiento BRENDA (Volpicelli et al., 2001). Por tanto cualquier intervención motivacional, orientada hacia la reducción del consumo de alcohol y la buena adherencia al tratamiento, pueden ser de utilidad para optimizar la eficacia de nalmefeno.

Conviene hacer un buen análisis de los patrones de consumo (de alcohol) del paciente, darle instrucciones y recomendaciones (verbales y por escrito), sobre la reducción del consumo y el manejo de nalmefeno (que sean claras y sencillas), y hacer un seguimiento posterior para favorecer el aprendizaje progresivo de este nuevo procedimiento terapéutico, ayudándole a superar los posibles obstáculos e incidencias que vayan apareciendo, a lo largo del tratamiento.

La participación activa del paciente alcohólico, en la decisión inicial del objetivo terapéutico de reducción del consumo y en el manejo individualizado del tratamiento, mejora la adherencia y la retención en programa de tratamiento. Es el mismo paciente quien decide cuando va a tomar la medicación e incluso cuando va a tomar o no tomar una consumición alcohólica. Se adapta mejor a los propios objetivos del paciente y evita que un consumo puntual se convierta en una recaída, ayudándole a superar con éxito las situaciones de riesgo de recaída. Si el paciente no considera un consumo puntual como una recaída, es decir, si no tiene la sensación de que ya ha recaído, es menos probable que abandone el programa de tratamiento. Su permanencia en el tratamiento facilita la relación médico-enfermo, ofreciéndole más oportunidades para que tome conciencia del problema, cambie progresivamente de actitud con respecto al consumo de alcohol, y reduzca de manera progresiva su tendencia a beber en exceso.

Entre las ventajas del tratamiento con nalmefeno cabe destacar (1) una mejor aceptación, por parte del paciente, probablemente debido a su mayor participación e implicación en la toma de decisiones. (2) Un efecto más específico sobre el síntoma "dificultad para controlar" el consumo de alcohol, que favorece la comprensión del mecanismo de acción de nalmefeno, tanto para el propio paciente como para sus familiares. (3) Aumenta la probabilidad de que el paciente solicite tratamiento y de que lo haga en una etapa más precoz de su enfermedad alcohólica. (4) En tal caso, permitiría detener la evolución de su enfermedad alcohólica desde las etapas iniciales, evitando la ampliación y el empeoramiento progresivo de las consecuencias negativas del consumo excesivo de alcohol, que habrían llegado a sufrir en el futuro, tanto el paciente alcohólico como sus familiares. (5) El tratamiento con nalmefeno es seguro, bien tolerado, sencillo y no requiere psicoterapia, sino sólo las instrucciones del médico experto.

A lo largo del tratamiento con nalmefeno, en cada visita se puede efectuar un análisis de los factores que aumentan el riesgo de descontrol en el consumo y trabajar las estra- tegias de afrontamiento para conseguir que el paciente mantenga un consumo de bajo riesgo. Además, se puede profundizar en el diagnóstico de comorbilidad psiquiátrica asociada (trastornos de ansiedad, afectivos o de personalidad) y detectar un posible consumo concomitante de otras drogas o medicamentos de abuso, que pueden interferir en la recuperación del alcoholismo. Estos datos enriquecen la comprensión diagnóstica personalizada de cada paciente alcohólico y permiten optimizar la evolución del paciente

Si el paciente está motivado para el tratamiento, es más probable que esté dispuesto a cambiar de actitudes, conductas, estilo de vida, etc.; lo cual resulta imprescindible para que pueda progresar en su recuperación. Si durante el tratamiento con nalmefeno se produce algún nuevo consumo excesivo de alcohol, es más probable que el paciente acuda a pedir ayuda y, si se hace un buen análisis de dicha recaída, el paciente puede aceptar mejor un nuevo plan de tratamiento, que posiblemente habría rechazado al inicio del tratamiento, debido a que todavía no había tomado conciencia de la gravedad del problema.

Finalmente, conviene tener en cuenta que nalmefeno es el único medicamento que tiene aprobada la indicación, por las autoridades sanitarias, para reducir el consumo en pacientes con dependencia del alcohol.

\section{Conclusiones}

1. Los fármacos antagonistas de los receptores opioides (nalmefeno y naltrexona) producen una reducción del consumo de alcohol.

2. Los antagonistas de los receptores opioides pueden evitar que un consumo puntual de alcohol se acabe convirtiendo en una recaída, dado que pueden atenuar el efecto de deprivación.

3. Tanto naltrexona como nalmefeno, consiguen una reducción del craving -tras un primer consumo de alcohol-, del número de consumiciones alcohólicas tomadas -por ocasión-, de la elección de una consumición alcohólica (ante la opción de tomar otra sin alcohol) y del efecto euforizante del alcohol.

4. El objetivo de tratamiento basado en la reducción del consumo de alcohol, puede conseguir los mismos resultados que la abstención continuada, siempre que el paciente no exceda los límites del consumo de bajo riesgo, en cada ocasión de beber.

5. Nalmefeno podría ser más eficaz que naltrexona, para reducir el consumo de alcohol, en las personas que tienen alcoholismo, gracias a su efecto modulador sobre los receptores kappa opioides.

6. Nalmefeno ayuda a que la persona que se propone reducir su consumo de alcohol pueda llegar a conseguirlo.

7. El perfil del paciente ideal sería probablemente el de una persona de mediana edad, que tiene una dependencia (del alcohol) de baja o moderada gravedad, que 
no presenta un claro síndrome de abstinencia del alcohol, que es la primera vez que solicita tratamiento del alcoholismo, que no tiene una grave comorbilidad médica, psiquiátrica, ni adictiva y que se propone conseguir una reducción sustancial de su consumo de alcohol.

8. Entre las ventajas cabe destacar que el tratamiento con nalmefeno es seguro, bien tolerado y sencillo, que no requiere psicoterapia sino apoyo psicosocial o las instrucciones del médico experto y que tiene una mejor aceptación, probablemente debido a la mayor participación del paciente en la toma de decisiones.

9. El tratamiento con nalmefeno, orientado a la reducción del consumo de alcohol, se adapta mejor a la demanda de la mayoría de los pacientes que inician el tratamiento del alcoholismo y puede favorecer la aceptación, la adherencia, la retención en el programa de tratamiento y el compromiso con este nuevo objetivo terapéutico.

10. Nalmefeno es el único fármaco que tiene aprobada la indicación -por parte de las autoridades sanitarias- para reducir el consumo de alcohol.

\section{Conflicto de intereses}

El autor ha participado como investigador principal en el estudio ESENSE 2 y ha formado parte del comité asesor sobre nalmefeno del Lundbeck España.

\section{Referencias}

Altshuler, H. L., Phillips, P. E. y Feinhandler, D. A. (1980). Alterations of ethanol self-administration by naltrexone. Life Sciences, 26, 679-688.

Anton, R. F., Pettinati, H., Zweben, A., Kranzler, H. R., Johnson, B., Bohn, M. J.,... Karhuvaara, S. (2004). A mulisite dose ranging study of nalmefene in the treatment of alcohol dependence. Journal of Clinical Psychopharmacology, 24, 421-428.

Anton, R. F., O’Malley, S. S., Ciraulo, D. A., Cisler, R. A., Couper, D., Donovan, D. M.,... Zweben, A., COMBINE Study Research Group. (2006). Combined pharmacotherapies and behavioral interventions for alcohol dependence the COMBINE study: a randomized controlled trial. Journal of American Medical Association, 295, 2003-2017.

Anton, R. F. (2008). Naltrexone for the management of alcohol dependence. New England Journal of Medicine, 359 , 715-721.

Arias, A. J., Armeli, S., Glernter, J., Covault, J., Kallio, A., Karhuvaara, S.,... Kranzler, H. R. (2008). Effects of opioid receptor gene variation on targeted nalmefene treatment in heavy drinkers. Alcoholism: Clinical and Experimental Research, 32, 1159-1166.

Berg, B. J., Pettinati, H. M. y Volpicelli, J. R. (1996). Valoración riesgo-beneficio de la naltrexona en el tratamiento de la dependencia del alcohol. Drug Safety, 15, 274-282.
Bouza, C., Magro, A., Muñoz, A. y Amate, J. M. (2004). Efficacy and safety of naltrexone and acamprosate in the treatment of alcohol dependence: a thematic review. Addiction, 99, 811-828.

Chick, J., Anton, R., Checinski, K., Croop, R., Drummond, D. C., Farmer, R.,... Ritson, B. (2000). A multicentre, randomized, double-blind, placebo-controlled trial of naltrexone in the treatment of alcohol dependence or abuse. Alcohol Ẽ Alcoholism, 35, 587-593.

Ciraulo, D. A., Dong, Q., Silverman, B. L., Gastfriend, D. R. y Pettinati, H. M. (2008). Early treatment response in alcohol dependence with extended-release naltrexone. Journal of Clincal Psychiatry, 69, 190-195.

Clapp, P., Bhave, S. V. y Hoffman, P. L. (2008). How adaptation of the brain to alcohol leads to dependence. A pharmacological perspective. Alcohol Research $\mathcal{E}$ Health, 31, 310-339.

Collins, M. A. y Bigdeli, M. B. (1975). Tetrahydroisoquinolines in vivo. Rat brain formation of salsolinol, a condensation product of dopamine and acetaldehyde under certain conditions during ethanol intoxication. Life Sciences, 16, 535-601.

Croop, R. S., Faulkner, E. B. y Labriola, D. F. (1997). The safety profile of naltrexone in the treatment of alcoholism. Results from a multicenter usage study. Archives of General Psychiatry, 54, 1130-1135.

Davidson, D., Palfai, T., Bird, Ch. y Swift, R. (1999). Effects of naltrexone on alcohol self-administration in heavy drinkers. Alcoholism: Clinical and Experimental Research, 23, 195-203.

Davis, V. E. y Walsh, M. D. (1970). Alcohol, amines and alkaloids; a possible basis for alcohol addiction. Science, 167, 1005-1007.

Drobes, D. J., Anton, R. F., Thomas, S. E. y Voronin, K. (2004). Effects of naltrexone and nalmefene on subjective response to alcohol among non-treatment-seeking alcoholics and social drinkers. Alcoholism: Clinical and Experimental Research, 28, 1362-1370.

European Medicines Agency. (2013). Selincro (nalmefene): EU summary of product characteristics. http:// www.emea.europa.eu/docs/en_GB/document_library/EPARProduct_Information/ European Medicines Agency. Selincro (nalmefene): EU summary of product characteristics. http://www.emea.europa.eu/ docs/en_GB/document_library/EPAR_Product_Information/human/002583/WC500140255.pdf. Accessed 28 June 2013.

Falk, D., Wang, X. Q., Liu, L, Fertig, J., Mattnson, M., Ryan, M.,... Litten, R. Z. (2010). Percentage of subjects with no heavy drinking days: evaluation as an efficacy endpoint for alcohol clinical trials. Alcoholism: Clinical and Experimental Research, 34, 2022-20343.

Froehlic, J. C., Harts, J., Lumeng, L., Li, T. K. (1990). Naloxone attenuates voluntary ethanol intake in rats selec- 
tively bred for high ethanol preference. Pharmacology Biochemistry and. Behavior, 35, 385-390.

Froehlic, J. C., Zweifel, M., Harts, J., Lumeng L. y Li, T. K. (1991). Importance of delta opioid receptors in maintaining high alcohol drinking. Psychopharmacology (Berlin), 103, 467-472.

Froehlic, J. C., Li, T. K. (1993). Opioid peptides. In: Galanter, M. (Ed.) Recent Developments in Alcoholism, Volume 11: Ten Years of Progress. New York: Plenum Press.

Garbutt, J. C., Kranzler, H. R., O’Malley, S. S., Gastfriend, D. R., Pettinati, H.M., Silverman, B. L.,... Ehrich, E. W. for the Vivitrex Study Group. (2005). Efficacy and tolerability of long-acting injectable naltrexone for alcohol dependence. Journal of American Medical Association, 293, $1617-1625$.

Gennazi, A. R., Nappi, G., Eacchinetti, F., Mezzella, G. L., Parrini, D., Sinforiani, E.,... Savoldi, F. (1982). Central deficiency of beta-endorphin in alcoholic addicts. Journal of Clinical Endocrinology and Metabolism, 55, 583-586.

Gianoulakis, C. (1993). Endogenous opioids and excessive alcohol consumption, Journal of Psychiatry and Neuroscience, $18,148-156$.

Gianoulakis, C., Kirshnan, B. y Thavundayil, J. (1996). Enhanced sensitivity of pituitary b-endorphin to ethanol in subjects at high risk of alcoholism. Archives of General Psychiatry, 53, 250-257.

Gonzalez, J. P. y Brogden, R. N. (1988). Naltrexone. A review of its pharmacodynamic and pharmacokinetic properties and therapeutic efficacy in the management of opioid dependence. Drugs, 35, 192-213.

Greenwald, R. D., Fertel, R. H., Wong, J. K., Schwartz, R. D. y Bianchine, J. R. (1979). Salsolinol and tetrahydropapaveroline bind opiate receptors in the brain. Federation proceedings, 63rd Annual Meeting.

Gual, A., He, Y., Torup, L., van den Brink, W. y Mann, K. (2013). A randomised, double-blind, placebo-controlled, efficacy study of nalmefene, as-needed use, in patients with alcohol dependence. European Neuropsychopharmacology 23, 1432-1442. doi: 10.1016/j.euroneuro.2013.02.006.

Guardia, J., Caso, C., Arias, F., Gual, A., Sanahuja, J., Ramírez, M.,... Casas, M. (2002). A double-blind, placebo-controlled study of naltrexone in the treatment of alcohol-dependence disorder. Results from a multicenter clinical trial. Alcoholism: Clinical and Experimental Research, 26, 1381-1387.

Guardia Serecigni, J., Jiménez Arriero, M. A., Pascual Pastor, F., Flórez Menéndez, G. y Contel Guillamón, M. (2008). Alcoholismo. Guía clínica de Socidrogalcohol basada en la evidencia científica. 2a Edición. Barcelona. SOCIDROGALCOHOL.

Guardia, J., Surkov, S. y Cardús, M. (2010). Neurobiología de la Adicción. En C. Pereiro (Ed.) Manual de Adicciones. (pp. 37-130). Barcelona. Socidrogalcohol.
Guardia Serecigni, J. (2011). Cambio de paradigma en el tratamiento del alcoholismo de baja gravedad. Adicciones, 23, 299-316.

Guardia, J., Surkov, S. y Cardús, M. (2011). Bases neurobiológicas de la Adicción. En J. Bobes, M. Casas, M. Gutiérrez (Eds.). Manual de Trastornos Adictivos. $2^{\mathrm{a}}$ Edición. (pp. 25-33). Valladolid. ADAMED. Enfoque Editorial.

Guardia Serecigni, J. (2015). La reducción del consumo de alcohol. Un nuevo objetivo en el tratamiento del alcoholismo de baja gravedad. Adicciones, 27, 3-7.

Gueorguieva, R., Wu, R., Pittman, B., Cramer, J., Rosenheck, R. A., O’Malley, S. S. y Krystal, J. H. (2007). New insights into the efficacy of naltrexone based on trajectory-based reanalyses of two negative clinical trials. Biological Psychiatry, 61, 1290-1295.

Heinala, P., Alho, H., Kiianmaa, K., Lonnqvist, J. y Sinclair, J. D. (2001). Targeted use of naltrexone without prior detoxification in the treatment of alcohol dependence: a factorial double-blind, placebo-controlled trial. Journqal of Clinical Psychopharmacology, 21, 287-292.

Hernández-Ávila, C. A., Song, Ch., Kou, L., Tennen, H., Armeli, S. y Kranzler, H. R. (2006). Targeted versus daily naltrexone: second analysis of effects on average daily drinking. Alcoholism: Clinical and Experimental Research, 30, 860-865.

Ingman, K., Hagelberg, N., Aalato, S., Nagren, K., Juhakoski, A., Karhuvaara, S.,... Scheinin, H. (2005). Prolonged central mu-opioid receptor occupancy alter single and repeated nalmefene dosing. Neuropsychopharmacology, 30, 2245-2253.

Johnson, S. W. y North, R. A. (1992). Opioids excite dopamine neurons by hyperpolarization of local interneurons. Journal of Neuroscience, 12, 483-488.

Johnson, B. A., Ait-Daoud, N., Bowden, Ch. L., Di Clemente, C., Roache, J. D., Lawson, K. (2003) Oral topiramamte for the treatment of alcohol dependence: a randomised controlled trial. The Lancet 361, 1677-1685.

Johnson, B. A., Rosenthal, N., Capece, J. A., Wiegand, F., Mao, 1., Beyers, K.,... Swift, R. M. (2007). Topiramate for treating alcohol dpendence. A randomized controlled trial. Journal of American Medical Association 298, 16411651.

Kalivas, P. W. y Volkow, N. D. (2005). The neural basis of addiction: a pathology of motivation and choice. American Journal of Psychiatry, 162,1403-1413.

Karhuvaara, S., Simojoki, K., Virta, A., Rosberg, M., Loyttiniemi, E., Nurminen, T.,... Makela, R. (2007). Targeted nalmefene with simple medical management in the treatment of heavy drinkers: a randomized double-blind placebo-controlled multicenter study. Alcoholism: Clinical and Experimental Research, 31, 1179-1187.

Keating, G. M. (2013). Nalmefene: A review of its use in the treatment of alcohol dependence. CNS Drugs, 27, 761-772. 
Kissler, J. L., Sirohi, S., Reis, D. J., Jansen, H. T., Quock, R. M., Smith, D. G. y Walker, B. M. (2013). The one-two punch of alcoholism: role of central amygdale dynorphins/kappa-opioid receptors. Biological Psychiatry, 75, 774-782. doi:10.1016/j.biopsych.2013.03.014.

Kornet, M., Goosen, C. y Van Ree, J. M. (1990). The effect of interrupted alcohol supply on spontaneous alcohol consumption by rhesus monkeys. Alcohol and Alcoholism, 25, 407-412.

Kornet, M., Goosen, C. y Van Ree, J. M. (1991). The effect of naltrexone on alcohol consumption during chronic alcohol drinking, and after a period of imposed abstinence in free-choice drinking rhesus monkeys. Psychopharmacology (Berlin), 104, 367-376.

Kranzler, H. R., Modesto-Lowe, V. y Van Kirk, J. (2000). Naltrexone vs. nefazodone for the treatment of alcohol-dependence. A placebo-controlled trial. Neuropsychopharmacology, 22, 493-503.

Kranzler, H. R., Tennen, H., Armeli, S., Chan, G., Covault, J., Arias, A. y Oncken, C. (2009). Targeted naltrexone for problem drinkers. Journal of Clinical Psychopharmacology, 29, 350-357.

Krystal, J. H., Cramer, J. A., Krol, W. F., Kirk, G. F. y Rosenheck, R. A, for the Veterans Affairs Naltrexone Cooperative Study 425 Group. (2001). Naltrexone in the treatment of alcohol dependence. New England Journal of Medecine, 345, 1734-1739.

Li, X. W., Li, T. K., Froehlic, J. C. (1992). The encephalinergic system and alcohol preference. Alcoholism: Clinical and Experimental Research, 16, 359.

Lucey, M. R., Silverman, B. L., Illeperuma, A. y O'Brien, C. P. (2008). Hepatic safety of once-monthly injectable extended-release naltrexone adminstered to actively drinking alcoholics. Alcoholism: Clinical and Experimental Research, 32, 498-504.

Mann, K., Bladstrom, A., Torup, L., Gual, A. y van den Brink, W. (2013). Extending the treatment options in alcohol dependence: a randomized controlled study of as-needed nalmefene. Biological Psychiatry, 73, 706713.

Mason, B. J., Ritvo, E. C., Morgan, R. O., Salvato, F. R. , Goldberg, G., Welch, B. y Mantero-Atienza, E. (1994). A doble-blind placebo-controlled pilot study to evaluate the efficacy and safety of oral nalmefene HCL for alcohol dependence. Alcoholism: Clinical and Experimental Research, 18, 1162-1167.

Masson, B. J., Salvato, F. R., Williams, L. D., Ritvo, E. C. y Cutler, R. B. (1999). A double-blind placebo-controlled study of oral nalmenfene for alcohol dependence. Archives of General Psychiatry, 56, 719-724.

Matz, J., Graff, C., Vainio, P. J., Kallio, A., Hojer, A. M., Struijk, J. J.,... Toft, E. (2011). Effect of namefene 20 and $80 \mathrm{mg}$ on the corrected QT interval and T-wave morphology: a randomized, double-blind, parallel-group, placebo- and moxifloxacin-controlled, single-centre study. Clinical Drug Investigation, 31, 799-811.

Nealey, K. A., Smith, A. W., Davis, S. M. y Walker, B. M. (2011). K-opioid receptors are implicated in the increased potency of intra-accumbens nalmefene in ethanol-dependent rats. Neuropharmacology, 61, 35-42.

Nestler, E. J., Hope, B. T. y Widnell, K. L. (1993). Drug addiction: A model for the molecular basis of neural plasticity. Neuron, 11, 995-1006.

Niciu, M. J. y Arias, A. J. (2013). Targeted opioid receptor antagonists in the treatment of alcohol use disorders. CNS Drugs, 27, 777-787.

Nutt, D. J. (2014). The role of the opioid system in alcohol dependence. Journal of. Psychopharmacology 28, 8-22. DOI: $10.1177 / 0269881113504017$.

O’Brien, C. P., Volpicelli, L. A. y Volpicelli, J. R. (1996). Naltrexone in the treatment of alcoholism: A clinical review. Alcohol, 13, 35-39.

O’Malley, S. S., Jaffe, A., Chang, G., Schttenfeld, R. S., Meyer, R. E. y Rounsaville, B. (1992). Naltrexone and coping skills therapy for alcohol dependence a controlled study. Achives of General Psychiatry, 49, 881-887.

Ortiz Camuñez, M. A. (1996). Naltrexona. Terapéutica en Atención Primaria de Salud, 3, 535-540.

Oslin, D. W., Lynch, K. G., Pettinati, H. M., Kampman, K. M., Gariti, P., Gelfand, L.,... O’Brien, C. P. (2008). A placebo-controlled randomized clinical trial of naltrexone in the context of different levels of psychosocial intervention. $\mathrm{Al}$ coholism: Clinical and Experimental Research, 32, 1299-1308.

Pascual Pastor, F., Guardia Serecigni, J., Pereiro Gómez, C. y Bobes García, J. (2013). Alcoholismo. Guías Clinicas de SOCIODROGALCOHOL bsadas en la EVIDENCIA CIENTÍFICA. $3^{a}$ Edición. Madrid. SANED (Sanidad y Ediciones).

Pettinati, H. M., O’Brien, C. P., Rabinowitz, A. R., Wortman, S. P., Oslin, D. W., Kampman, K. M. y Dackis, C. A. (2006). The status of naltrexone in the treatment of alcohol dependence: specific effects on heavy drinking. Journal of Clinical Psychopharmacology, 26, 610-625.

Rehm, J., Baliunas, D., Borges, G. L., Graham, K., Irving, H., Kehoe, T.,... Taylor, B. (2010). The relation between different dimensions of alcohol consumption and burden of disease: an overview. Addiction 105, 817-843.

Reid, L. D. (1990). Summary. In L. D. Reid (ed.) Opioids, bulimia and alcohol abuse $\mathcal{E}$ alcoholism (pp. 289-304). New York: Springer-Verlag.

Rösner, S., Hackl-Herrweth, A., Leucht, S., Vecchi, S., Srisurapanant, M. y Soyka, M. (2010). Opioid antagonists for alcohol dependence. Cochrane Database Syst Rev, 12, CD001867.

Seizinger, B. R., Hollt, V. y Herz, A. (1984). Effect of chronic ethanol treatment on the in vitro biosynthesis of pro-opiomelanocortin and its post-translational processing to b-endorphin in the intermediate lobe of the rat pituitary. Journal of Neurochemistry, 43, 607-613. 
Shippenberg, T. S., Zapata, A. y Chefer, V. I. (2007). Dynorphin and the pathophysiology of drug addiction. Pharmacology and Therapeutics, 116, 306-321.

Siegel, S. (1986). Alcohol and opiate dependence: Re-evaluation of the Victorian perspective. In H.D. Capell, F. B. Glaser, Y. Israel, et al. (Eds.): Research Advances in Alcohol and Drug Problems. (pp. 279-314). New York: Plenum Press.

Sinclair, J. D. (1990). Drugs to decrease alcohol drinking. Annals of Medicine, 22, 357-362.

Sinclair, J. D. (2001). Evidence about the use of naltrexone and for different ways of using it in the treatment of alcoholism. Alcohol and Alcoholism, 36, 2-10.

Sirohi, S., Bakalkin, G. y Walker, B. M. (2012). Alcohol-induced plasticity in the dynorphin/kappa-opioid receptor system. Frontiers in Molecular Neuroscience, 5, 1-12.

Spanagel, R., Herz, A. y Shippenbeerg, T. S. (1992). Opposing tonically active endogenous opioid systems modulate the mesolimbic dopaminergic pathway. Proceeding of National Academy of Sciences, 89, 2046-2050.

Spanagel, R. y Vengeliene, V. (2012). New pharmacological treatment strategies for relapse prevention. Current Topics in Behavioral Neurosciences, 13, 583-609.

Srisurapanont, M. y Jarusuraisin, N. (2005). Naltrexone for the treatment of alcoholism: a meta-analysis of randomized controlled trials. International Journal of Neuropsychopharmacology, 8, 267-280.

Swift, R. M., Whelihan, W., Kuznetson, O., Buongiorno, G. y Hsuing, H. (1994). Naltrexone-induced alterations in human ethanol intoxication. American Journal of. Psychiatry, 151, 1463-1467.

Terenius, L. (1996). Alcohol addiction (alcoholism) and the opioid system. Alcohol, 13,31-34.

Van den Brink, W., Aubin, H.J., Bladström, A., Torup, L., Gual, A. y Mann, K. (2013). Efficacy of as-needed nalmefene in alcohol-dependent patients with at least a high drinking risk level: results of a subgroup analysis of two randomized controlled 6-month studies. Alcohol and Alcoholism, 48: 570-578.

Van den Brink, W., Sørensen, P., Torup, L., Mann, K. y Gual, A., for the SENSE Study Group. (2014). Long-term efficacy, tolerability and safety of nalmefene as-needed in patients with alcohol dependence: A 1-year, randomised controlled study. Journal of Psychopharmacology, 28, 733744. DOI: 10.1177/026988111452/362.

Van Ree, J. M. (1987). Reward and abuse: opiates and neuropeptides. In J. Engel, \& L. Oreland (Eds.). Brain Reward Systems and Abuse. New York: Raven press.

Volpicelli, J. R., Ulm, R. R. y Hopson, N. (1991). Alcohol drinking in rats during and following morphine injections. Alcohol, 8, 288-292.

Volpicelli, J. R., Alterman, A. I., Hayashida, M. y O’Brien, C. P. (1992). Naltrexone in the treatment of alcohol dependence. Archives of General Psychiatry, 49, 876-880.

Volpicelli, J. R., Watson, N. T., King, A. C., Sherman, C. E. y O'Brien, Ch. P. (1995). Effect of Naltrexone on Alcohol "high" in alcoholics. American Journal of Psychiatry, 152, 613-615.

Volpicelli, J. R., Pettinati, H. M., McLellan, A. T. y O'Brien, C. P. (2001). Combining Medication and Psychosocial Treatments for Addictions. The BRENDA approach. The Guilford Press: New York.

Walker, B. W. y Koob, G. (2008). Pharmacological evidence for motivational role of kappa-opioid systems in ethanol dependence. Neuropsychopharmacology, 33, 643-652.

Walker, B. W., Zorrilla, E. P. y Koob, G. F. (2011). Systemic k-opioid receptor antagonism by norbinaltorphimine reduces dependence-induced excessive alcohol self-administration in rats. Addiction Biology, 16, 116-119.

Wise, R. A. y Bozarth, M. A. (1982). Action of drugs of abuse on brain reward systems: an update with specific attention to opiates. Pharmacology Biochemistry and Behavior, 17, 239-243.

Work Group on Substance Use Disorders. (2007). Treatment of patients with substance use disorders, second edition. American Psychiatric Association Practice Guidelines. American Journal of Psychiatry, 164, 4.

World Health Organization (2000). International Guide for Monitoring Alcohol Consumption and Related Harm. Geneva: WHO. 